\title{
LEITURA COLETIVA DE UM TEXTO DE LITERATURA INFANTIL NO ENSINO FUNDAMENTAL: ALGUMAS MEDIAÇÕES PENSANDO O ENSINO DAS CIÊNCIAS ${ }^{1}$
}

\author{
Collective reading of a text of children literature in the school: some mediations \\ thinking the science teaching
}

\author{
Carla Giulia Corsi Moreira Giraldelli ${ }^{2}$ \\ Maria José P. M. de Almeida
}

\begin{abstract}
RESUMO
Analisamos o funcionamento de um texto de literatura infanto-juvenil, como mediador, no ensino de ciências naturais para crianças de nove a dez anos de idade numa classe de quarta série do ensino fundamental de uma escola pública na cidade de Campinas - SP. A leitura coletiva do texto narrativo foi proposta com o intuito de incentivar a curiosidade dos estudantes e contribuir para a construção de concepções pertinentes à área de Ciências de maneira prazerosa. A análise de falas das crianças ocorridas durante essa leitura e de textos por elas escritos após o término da atividade evidenciou mediações do texto, mediações criança-criança, e criança-professora pesquisadora. Pudemos notar que, além de prazerosa, a atividade desempenhou um papel significativo como instigadora de conhecimentos sistemáticos abstratos.
\end{abstract}

Palavras-chave: Ciências naturais; ensino fundamental; leitura.

\begin{abstract}
We analyse the functioning of a text of children's literature to mediate in the teaching of nature sciences for children from nine to ten years old in a classroom of the basic teaching of a public school in the Campinas city, state of São Paulo. The collective reading of the narrative text was considered with intention to stimulate the curiosity of the students and to contribute for the construction of pertinent conceptions to the area of Sciences in pleasant way. The analysis of children speaks occured during this reading and of texts written for them after the ending of the activity, it evidenced mediation of the text, mediation child-to-child, and child-to-researcher teacher. We could notice that, beyond pleasant, the activity played a significant role as investigator of abstract systematic knowledge.
\end{abstract}

Keywords: Nature sciences; basic teaching; reading.

\footnotetext{
${ }^{1}$ Este trabalho foi desenvolvido a partir de monografia da primeira autora para conclusão do curso de Pedagogia da Faculdade de Educação da Unicamp e reorganizado e ampliado a partir de uma comunicação no V Encontro Nacional de Pesquisa em Ensino de Ciências.

${ }^{2}$ Mestranda, gepCE - FE / UNICAMP, e-mail: carlagiraldelli@gmail.com. Apoio da Secretaria de Educação do Estado de São Paulo.

3 gepCE - FE / UNICAMP, e-mail:mjpma@unicamp.br. Apoio do Conselho Nacional de Desenvolvimento Científico e Tecnológico - CNPq
} 


\section{INTRODUÇÃO E JUSTIFICATIVA}

A realização deste trabalho está alicerçada numa série de pressupostos, que passamos a enunciar. Trata-se de um trabalho no ensino de Ciências e, por isso, julgamos relevante assinalar que a construção da Ciência não ocorre isoladamente de um conjunto de determinantes sociais, tecnológicos e de transformações econômicas, em espaço e tempo históricos, constituindo-se a própria Ciência também num determinante desses acontecimentos sociais.

Seguindo o mesmo raciocínio quanto ao ensino da Ciência, como afirma Arroyo (1988), não é possível separá-lo de processos sociais e políticos da sociedade. Separação em que aparentemente se acredita quando se pensa o ensino tendo em conta um único olhar, quer ele seja o da Psicologia Cognitiva, da Social, ou da Epistemologia da Ciência, entre outros possíveis alicerces para se pensar o ensino. Entretanto, ao fazermos este comentário não estamos descartando a relevância dos trabalhos assim pensados, sejam eles experiências de ensino ou resultados de pesquisa. Apenas gostaríamos de ressaltar a complexidade do ensino e da sua análise e o fato de que ao realizá-los fazemos escolhas que deixam sempre fora da pesquisa algumas das variáveis intervenientes no ensino.

Tendo essas observações em conta, pensamos a pesquisa aqui descrita buscando resultados que possibilitem um ensino de Ciências que não vise apenas a incorporação do saber científico acumulado e sistematizado historicamente, mesmo reconhecendo a relevância desse saber para o cidadão. Entretanto, com este trabalho visamos principalmente contribuir para a legitimação de um tipo de ensino que reconheça a importância de pensar em atitudes e habilidades, além dos conteúdos ensinados, tendo em vista contribuir para a construção da cidadania dos estudantes.

Por outro lado, sabemos que o conhecimento científico é necessariamente produzido de maneira fragmentada, e com freqüência essa fragmentação é exacerbada na escola, mesmo no ensino fundamental. Apesar da não divisão disciplinar neste nível de ensino, freqüentemente o professor divide o tempo de aula pelos conteúdos específicos a serem trabalhados, sem que haja relacionamento entre eles. É fato também que, algumas estratégias metodológicas, como as aulas expositivas, a solução 
de exercícios e as atividades experimentais, têm sido aparentemente, privilegiadas no ensino dos saberes próprios das Ciências Naturais.

Procurando contribuir para aumentar esse leque de possibilidades, pensamos nesta pesquisa o funcionamento da leitura tendo em vista a construção dos saberes das Ciências Naturais no ensino fundamental. Ao planejarmos uma atividade de leitura e analisarmos seu funcionamento, buscamos elementos que possam contribuir para que sejam, cada vez mais, construídas propostas prazerosas e significativas para a aprendizagem de concepções sobre Ciências Naturais, a partir da leitura.

Com esse propósito, e numa perspectiva de que a Ciência não é a dona da verdade, mas uma das formas de compreensão do mundo, e admitindo também que as motivações humanas não são naturais, pois são socialmente construídas, planejamos uma atividade que incluiu a leitura coletiva de um texto narrativo de literatura infantil. Dadas as próprias características do texto literário, usualmente propício a controvérsias e debates, admitimos que com essa atividade teríamos efetiva oportunidade de obter manifestações das crianças.

A atividade foi realizada numa sala da quarta série do ensino fundamental de uma escola pública estadual de Campinas. Lemos com as crianças um texto de literatura infanto-juvenil: "Tem um cabelo na minha terra!" (Gary Larson, 2002), que tem ilustrações com características de cartum e analisamos o funcionamento dessa leitura. Consideramos que esse texto possui interfaces entre o conhecimento biológico, o ambiental e a literatura, além de suscitar questões referentes ao comportamento e às ações humanas.

Entre os subsídios em que nos apoiamos para o planejamento da atividade destacamos elementos da teoria sociocultural de L. S. Vygotsky, concepções sobre a construção do conhecimento científico de G. Bachelard e de alguns autores que pensaram a questão da leitura. Já no que se refere às concepções de linguagem e aos subsídios para análise do funcionamento da atividade em classe nos pautamos na perspectiva da análise de discurso, principalmente em noções selecionadas em textos publicados no Brasil por E. Orlandi.

Além do já comentado, o planejamento da atividade se sustentou na convicção de que, na sala de aula, como mediador, o professor pode orientar os estudantes,

\footnotetext{
${ }^{4}$ LARSON, Gary. Tem um cabelo na minha terra!: uma história de minhoca. Tradução de Heloísa Jahn. Prefácio de Edward O. Wilson. São Paulo: Companhia das Letrinhas, 2002. (4 reimpressão)
} 
considerando as informações trazidas por eles e os instigando a ultrapassá-las, facilitando o desenvolvimento de uma postura reflexiva, questionadora e investigativa, por parte das crianças.

E, quanto à opção pela mediação de um texto, consideramos relevante a perspectiva de Almeida (1998), quando afirma que o texto escrito está presente na escola transmitindo informações, fornecendo instruções, provocando a reflexão e, modificando representações. Porém, isto pode se dar sem perder seu potencial de ações mecânicas e de simulações. Por outro lado, ele pode ser um eficaz mediador de conhecimentos.

Em sala de aula, o funcionamento de textos precisa ser compreendido, tendo em conta as interações que ali ocorrem, pois estão em jogo concepções e representações de ciência, de leitura e de ensino, além das expectativas mútuas, que condicionam os sujeitos no processo. Mais do que uma discussão a respeito do funcionamento de textos escritos, é preciso considerar as concepções de linguagem, ensino e ciência que estão em jogo no processo que se quer instaurar (Ricon e Almeida, 1991).

Pautando-nos nesses elementos, procuramos levar em conta interpretações das crianças e supondo o próprio texto e as relações estabelecidas em classe como mediadores de conhecimento: das crianças com a pesquisadora-professora, primeira autora desta apresentação, com a professora da classe e com as outras crianças da sala.

\section{LiTERATURA NO ENSINO DE CIÊNCIAS E O TEXTO SELECIONADO}

Almeida (1998), focalizando as aulas de Física em nível médio, remete para o uso de textos alternativos ao livro didático, tais como romances, poesias, livros de divulgação científica e textos jornalísticos. Nesse estudo, parte da consideração que livros didáticos e apostilas são basicamente o único recurso pedagógico utilizado na maioria das escolas e reconhece que a linguagem desse tipo de recurso é quase que exclusivamente a linguagem formal. Suas reflexões evidenciam qualidades do funcionamento do texto literário na escola, mas também lembram que não basta substituir um texto por outro: 


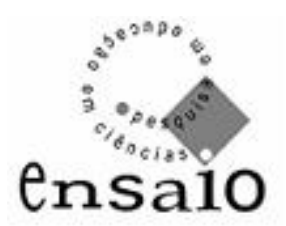

Vol. 10 no 1 jun. 2008

\begin{abstract}
Algumas respostas apontam para a transformação da qualidade do ensino com o uso e a análise do funcionamento de textos literários e de divulgação científica, bem como mostram um caminho possível para a atualização dos conteúdos em aulas de física, e, de outro lado, evidenciam que o simples uso ou a substituição de textos de um tipo por outros de natureza diferente não muda a qualidade da mediação escolar. (Almeida, 1998: 54)
\end{abstract}

Preocupada com a formação de leitores, Kaufman (1995) acredita que a sua formação ocorre a partir da leitura de uma diversidade de textos, e também fora da escola, leituras com múltiplos propósitos, como informar, entreter, argumentar, persuadir etc., que não se realizam com a única finalidade de cumprir as exigências de um programa, o que freqüentemente acontece na escola. Esta idéia evidentemente não descarta todos os textos escolares, pois eles podem favorecer os trabalhos de produção e de compreensão da linguagem, desde que utilizados convenientemente.

Também com relação à leitura, numa perspectiva discursiva, Orlandi (1988) diz haver alguns fatos que se impõem:

a) o de pensar a produção da leitura e, logo, a possibilidade de encará-la como possível de ser trabalhada (se não ensinada);

b) o de que a leitura, tanto quanto a escrita, faz parte do processo de instauração do(s) sentido(s);

c) o de que o sujeito-leitor tem suas especificidades e sua história;

d) o de que tanto o sujeito quanto os sentidos são determinados histórica e ideologicamente;

e) o fato de que há múltiplos e variados modos de leitura;

f) finalmente, e de forma particular, a noção de que nossa vida intelectual está intimamente relacionada aos modos e efeitos de leitura de cada época e segmento social.(p.8)

Dada a importância da leitura que esses fatos revelam, como, então, selecionar textos para realização de trabalho em sala de aula?

Segundo Kaufman (1995), selecionar materiais para leitura é uma das tarefas mais difíceis para o professor, independentemente do nível e modalidade da educação, pois implica avaliar, ou seja, utilizar juízos racionais em função de diversos critérios e o valor atribuído aos materiais, enquanto recursos didáticos. Aqui, são colocadas em 


\section{, \\ ensaio}

vol. 10 no 1 jun. 2008

jogo, diferentes concepções sobre aprendizagem, sobre leitura e seu funcionamento, funções dos textos, o universo do discurso e o papel do professor enquanto mediador na sala de aula; além das representações que cada docente tem do desenvolvimento cognitivo, sócio-afetivo e interesses dos sujeitos a quem são dirigidos os textos:

É preciso estar atento, por outro lado, para os conteúdos culturais que os textos escolares incorporam à transferência educativa. Todos os materiais de leitura enquanto linguagem transmitem modelos de vida, através dos quais o indivíduo aprende a desenvolver-se como membro de uma sociedade e a adotar sua cultura, seus modos de pensar e de agir, suas crenças e seus valores. (Halliday, 1982 apud Kaufman, 1995: 46)

E os conteúdos culturais não são a única preocupação necessária numa proposta de leitura em sala de aula. À diversidade e seleção adequada dos textos, soma-se o modo como os fazemos funcionar em classe, pois ao escolarizarmos materiais de circulação social, de riqueza imaginativa, podemos desviar seus propósitos e empobrecê-los, ao desenvolvermos atividades mecânicas, sem grandes desafios criativos de leitura, como recortar sílabas ou letras, sublinhar substantivos, adjetivos, advérbios e outros (Kaufman, 1995).

Quanto ao texto selecionado para leitura, o de Gary Larson (2002), "Tem um cabelo na minha terra!", segundo Edward O. Wilson no prefácio do livro, o autor considera o homem como parte da natureza e como organismo vivo; sujeito às mesmas leis físicas, integrado a teias alimentares, fluxos de energia, ciclos de nutrientes e predador-presa, imperativos territoriais e a prática de escravização entre algumas espécies. Além disso, traz a concepção de que para interferir na natureza, é preciso entendê-la.

O texto do livro é narrado com humor e irreverência, por uma "família" de minhocas e conta a história de uma donzela chamada Benedita, que mora na floresta e costuma sair observando e interferindo nas relações ali existentes, sem saber ao certo o que realmente acontece na natureza. A narrativa, toda ela construída de maneira divertida e instigante, utiliza como recurso o desafio ao imaginário a partir da construção de um diálogo entre o “pai Minhoco”, a “mãe Minhoca” e o "filho Minhoquinho”. Segundo Coelho (1997) estudar uma história é em primeiro lugar divertir-se com ela e na seleção desse texto procuramos ter essa premissa em conta.

Mas o texto não é apenas divertido; Larson insere uma moral ecológica na 


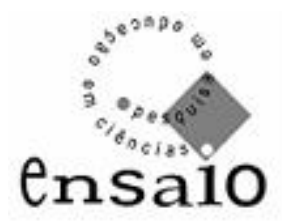

Vol. 10 no 1 jun. 2008

história, e vai mais longe: "a natureza faz parte de nós e nós fazemos parte dela". Explica, a partir da saga de Benedita, a dependência entre os organismos e o princípio ecológico da exploração mútua e a lei da sobrevivência, mostrando que o homem não está fora desse sistema. $\mathrm{O}$ autor explicita que, nós também somos organismos e, como tal, estamos sujeitos às mesmas leis.

Pela leitura do texto pode-se inferir que Larson quer evidenciar que, além de amar e reverenciar a natureza, nós precisamos, acima de tudo, compreendê-la, ou seja, ampliar nossos conhecimentos, do senso comum para o científico. Benedita, pela falta de conhecimentos sobre as inter-relações ambientais, acaba tendo um triste fim.

\section{A ConstruÇão do Conhecimento Científico Pelos Estudantes}

Para evidenciar nossa posição em relação à construção da Ciência partimos do que diz um educador que mostra em sua fala ter se baseado em posições de Gaston Bachelard. Como afirma Snyders (1978), ninguém insistiu mais do que Bachelard, sobre a necessidade de uma ruptura entre o pensamento imediato e a atitude do saber científico, ou seja, romper com os dados do senso comum, pois a atitude científica implica uma inversão de perspectiva. No entanto, Bachelard considera que essas rupturas encontram, finalmente, uma continuidade mais profunda com a experiência do aluno.

Ao defender o contrário das atitudes espontâneas do aluno, a explicação científica oferece-lhe, finalmente, os meios de pensar essas atitudes segundo um modo de coerência e de clareza, ao passo que a sua experiência se apresenta como esparsa, contraditória a si mesma (...). (Bachelard apud Snyders, 1978: 355)

O conhecimento do real, de acordo com Bachelard (1996) nunca é imediato e pleno; suas revelações são recorrentes, nunca é "o que se poderia achar", mas sempre, "o que se deveria ter pensado". O ato de conhecer acontece contra um conhecimento anterior, destruindo os conhecimentos mal estabelecidos, superando o que ele denominou de obstáculos epistemológicos, com lentidão, conflitos, estagnação e até regressão do conhecimento. Se não há questionamento, o conhecimento fica impregnado por um obstáculo epistemológico. 


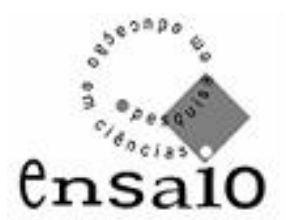

Vol. 10 no 1 jun. 2008

A racionalidade do conhecimento científico não é um refinamento da racionalidade do senso comum, mas, ao contrário, rompe com seus princípios, exige uma nova razão que se constrói à medida em que são suplantados os obstáculos epistemológicos. (Lopes, 1993, p.325)

Segundo Snyders (1978), Bachelard considera que é difícil para o aluno renunciar aos hábitos de espírito que foram formados na sua prática cotidiana, mas a atitude científica implica uma inversão de perspectiva. A explicação científica oferece ao indivíduo meios para ele pensar as atitudes espontâneas, de um modo coerente, pois quando rompe com os fatores filosóficos de unificação fácil, é que o progresso científico efetua suas etapas mais marcantes. Sempre lhe será possível sair da contemplação do mesmo para buscar o outro e tornar a experiência dialética. O homem, movido pelo espírito científico deseja saber, mas para melhor questionar. A Ciência é influenciada pelas próprias experiências e concepções. Mas, pouco a pouco somos levados a converter nossas objeções em objetos e a transformar nossas críticas, em leis. É preciso detectar os obstáculos epistemológicos para fundamentar os rudimentos da psicanálise da razão, pois "(...) é muito difícil estabelecer uma hierarquia do erro e seguir uma ordem determinada para descrever as desordens do pensamento" (Bachelard, 1996, p. 26).

Essas idéias contribuem para que possamos compreender a formação de conceitos como é concebida por Vygotsky (1993), que evidencia a importância do trabalho com os conceitos científicos para que a criança possa romper com os conceitos espontâneos. Como mediador, o professor assume a posição de orientador do desenvolvimento dos conceitos pela criança. Ela pode aprender com o adulto ou com outra criança, em cooperação. E o que hoje ela é capaz de realizar em cooperação, amanhã, poderá fazer sozinha. Portanto, o único aprendizado positivo é aquele que caminha à frente do desenvolvimento, servindo-lhe de guia, voltando-se não tanto para as funções já maduras, mas principalmente para as funções em amadurecimento na criança.

É na relação com o outro que a criança se apropria de significações, que possibilitam o acesso a formas culturais de perceber e estruturar a realidade. A partir dessas relações, o indivíduo constrói internamente as formas culturais. A criança internaliza conhecimentos mediante o estabelecimento de uma nova relação cognitiva 


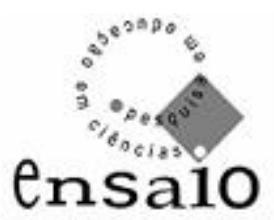

Vol. 10 no 1 jun. 2008

com o mundo e seu próprio pensamento, o que se dá durante o processo de educação formal ou não. Na escola, por exemplo, as condições se modificam, a criança raciocina com a professora; ela aprende significados, modos de agir, pensar e começa a se dar conta das atividades mentais que realiza e de seus conhecimentos (Vygotsky, 1988).

Na formação de conceitos pela criança, um conceito é mais do que a soma de conexões associativas formadas pela memória e mais do que um hábito mental; é um ato complexo de pensamento, realizado pela própria criança e para o qual pode contribuir a mediação do professor.

O desenvolvimento dos conceitos não-espontâneos, segundo Vygotsky (1993), deve possuir todos os traços peculiares ao pensamento, em cada nível de desenvolvimento da criança. Não são conhecimentos aprendidos mecanicamente, mas que evoluem com a ajuda de intensa atividade mental da própria criança. O desenvolvimento espontâneo e o não-espontâneo relacionam-se e influenciam-se constantemente, embora eles se desenvolvam em direções opostas. Não se trata de um conflito entre formas antagônicas, pois fazem parte de um único processo - o desenvolvimento da formação de conceitos, que é afetado por diferentes condições internas e externas.

Os conceitos científicos desenvolvem-se para baixo por meio dos conceitos espontâneos; os conceitos espontâneos desenvolvem-se para cima por meio dos conceitos científicos. (Vygotsky, 1993: 94)

Um nível mais elevado dos conceitos científicos eleva também o nível dos conceitos espontâneos. A partir do momento em que a criança já atingiu a consciência e o controle de um tipo de conceito, todos os conceitos formados anteriormente são reconstruídos da mesma forma.

E a escola tem um papel importante nesse movimento. Originários do aprendizado sistematizado em sala de aula ou da experiência pessoal da criança, os conceitos se formam sob condições diferentes, ou seja, a mente se defronta com problemas diferentes quando assimila os conceitos na escola ou quando é entregue aos seus próprios recursos.

O ensino, na visão vygotskyana, desempenha um papel importante na 


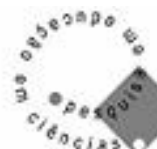 \\ ensa10}

Vol. 10 no 1 jun. 2008

internalização dos conceitos científicos, pois quando mediamos um conhecimento sistemático à criança, ensinamos-lhe muitos conceitos que ela não pode ver ou vivenciar diretamente. Nos conceitos científicos adquiridos na escola, a relação com o objeto é mediada por algum outro conceito. Os rudimentos de sistematização primeiro entram na mente do sujeito, por meio do seu contato com os conceitos científicos e depois são transferidos para os conceitos cotidianos, mudando sua estrutura psicológica de "cima para baixo".

O aprendizado escolar induz o tipo de percepção generalizante, desempenhando assim um papel decisivo na conscientização da criança dos seus próprios processos mentais. Os conceitos científicos, com o seu sistema hierárquico de inter-relações, parecem constituir o meio no qual a consciência e o domínio se desenvolvem, sendo mais tarde transferidos a outros conceitos e a outras áreas do pensamento. A consciência reflexiva chega à criança através dos portais dos conhecimentos científicos. (Vygotsky, 1993: 79)

As idéias aqui sintetizadas de Bachelard e Vygotsky tiveram importância decisiva na natureza da atividade que foi organizada em sala de aula com o livro de literatura infanto-juvenil de Larson. Recorrendo ao humor como meio para engendrar uma leitura prazerosa, o autor simultaneamente recheia seu texto de conceitos científicos relevantes que acreditamos que poderiam contribuir para que as crianças rompessem com alguns dos seus conceitos espontâneos sobre o ambiente. E quanto à estratégia de leitura, admitimos que a leitura coletiva faria com que ocorressem, além das mediações do texto, mediações criança-professora pesquisadora e também mediações criança-criança.

\section{ELEMENTOS DE ANÁLISE Do DISCURSO}

Admitimos que as mediações, a que nos referimos no item anterior, se fariam presentes nas significações das crianças, como leitoras e autoras, a partir do texto lido coletivamente. Para compreendermos suas interpretações nos pautamos em elementos da análise de discurso como é apresentada no trabalho de Orlandi (1996). A autora traz a questão da interpretação como relação entre ideologia e inconsciente, tendo 


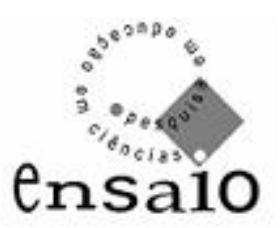

como meio material a linguagem.

Na análise do discurso, como é compreendida por Orlandi, a linguagem não é considerada transparente, pois ela supõe a existência da ideologia. Compreender as interpretações das crianças nessa perspectiva é explicitar o modo como um objeto simbólico produz sentido. No caso, a história lida, e as diferentes mediações que a atividade em classe possibilitou. A ideologia não está em um conteúdo determinado, mas está nos mecanismos que o produzem. "Dar sentido", para o sujeito que fala, é construir significações; tornar possíveis gestos de interpretação. Isto se dá a partir de uma relação entre pensamento, linguagem e mundo. É, portanto, um processo histórico da língua.

Se não nos ativermos aos conteúdos da linguagem, podemos procurar entender o modo como os textos produzem sentidos e a ideologia será então percebida como o processo de produção de um imaginário, isto é, produção de uma interpretação particular que apareceria, no entanto, como a interpretação necessária e que atribui sentidos fixos às palavras, em um contexto histórico dado. (Orlandi, 1996: 65)

A interpretação é sempre regida por condições específicas de produção, que aparecem como se fossem naturais, universais e eternas, pois a significação pelos sujeitos supõe necessariamente uma ideologia. Quando fala, o sujeito está interpretando, atribui sentido às suas palavras em condições específicas e ele o faz como se os sentidos estivessem nas palavras, desaparecendo suas condições de produção, e a interpretação parece-lhe transparente. Portanto, na ideologia não há ocultação de sentidos, mas apagam-se os processos de sua constituição. A interpretação não é mero gesto de decodificação e de apreensão de sentido, mas também não é livre de determinações.

E as significações são simultaneamente estrutura e acontecimento. A história se inscreve na língua e a significa. A interpretação do autor supõe a repetição, mas não como o mesmo; como algo passível de interpretação, ou seja, o que é pré-constituído é passível de ser repetido na relação com o interdiscurso. Afinal, "para que uma palavra faça sentido, é preciso que ela já tenha sentido" (Orlandi, 1996: 71). O interdiscurso seria o domínio da memória discursiva, o que sustenta o dizer de formulações já feitas e "esquecidas" e que vão construindo uma história dos sentidos. Estes não retornam apenas, mas são transformados e re-significados. 


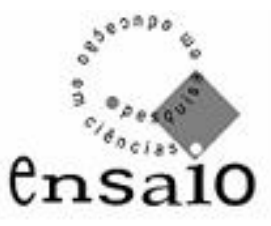

Vol. 10 no 1 jun. 2008

\section{O fUncionamento do TeXto em Sala de Aula}

A leitura coletiva ocorreu numa sala com 29 crianças de 9 e 10 anos de idade, numa escola estadual de Campinas - SP. Como afirma Silva (2002), a sala de aula é um espaço onde se produzem, reproduzem determinados sentidos e se apagam ou ocultam outros sentidos.

O contexto escolar tem história própria e deve ser levado em consideração na produção dos sentidos, neste caso, com relação à leitura do texto. A mediação do professor é fundamental nesse processo. Daí a relevância de conhecermos o trabalho que vinha sendo desenvolvido pela professora da classe com as crianças, mesmo sabendo que esse trabalho constituiu apenas parte das suas histórias de vida.

No sentido de se apropriar, ainda que parcialmente, e apenas de parte dessa história de vida, o trabalho desenvolvido pela pesquisadora não se restringiu à leitura com as crianças, mas envolveu alguns momentos anteriores à leitura propriamente dita: reconhecimento do espaço escolar, contato com professores, funcionários e direção; uma primeira conversa com os alunos: apresentações e observação das atividades que eles estavam desenvolvendo. Essas interações preliminares, além de familiarizarem a pesquisadora com a situação em que atuaria como professora, também lhe possibilitaram algum reconhecimento do contexto onde os discursos das crianças seriam produzidos durante a atividade.

Os momentos seguintes foram: leitura do texto infantil com as crianças e gravação dessa leitura; elaboração, pelos estudantes, de carta a um amigo, contando sobre a história lida; agradecimento à professora, alunos, direção e um pedido de autorização dos autores para que as cartas pudessem ser divulgadas. Neste artigo analisamos apenas falas do movimento discursivo ocorrido durante a leitura.

No dia da leitura, as crianças foram convidadas a se posicionarem em "U", na sala de aula, visando possibilitar uma maior interação entre elas. Foram distribuídos quatorze exemplares do livro: um para cada duas crianças. E a leitura foi feita principalmente pela pesquisadora, sendo toda a atividade gravada. A professora da classe permaneceu observando, mas não interferiu na atividade que estava sendo desenvolvida.

A transcrição de alguns diálogos apresentados a seguir evidencia o quanto as 


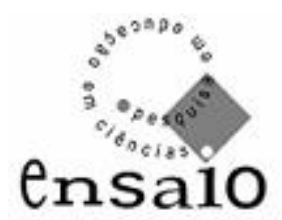

Vol. 10 no 1 jun. 2008

crianças participaram e se interessaram pela obra, significando-a. Neles vemos o funcionamento da leitura coletiva, e podemos notar como os sentidos produzidos pelas crianças não se devem apenas ao próprio texto, mas são resultado do processo de leitura, do qual fazem parte os sujeitos leitores, suas histórias de vida e de leitura. (Orlandi, 1988):

Pesquisadora: "- Hoje nós vamos ler um livro chamado 'Tem um cabelo na minha terra! - uma história de minhoca'. Estão vendo um 'minhoquinho', aí?"

Algumas crianças: "- Que legal, tia!"

Pesquisadora, lendo: "- (...)'Detesto ser minhoca!', guinchava, e seu corpo minúsculo tremia inteiro. (...)' Todo mundo sabe o que é guinchava?"

Gustavo $^{5}$ : "- É gritava, tia."

Lucas: "- Olha tia! A mãe tá falando: - Acho que faltou um pouco de orégano!"

Pesquisadora: "- Olhem a Benedita na porta da casa."

Lucas: "- Benedita cabrita! Benedita cabrita!"

Pesquisadora: "- Podemos continuar?"

As crianças, em coro: "- Podemos!"

Nas falas das crianças nesses três trechos, além do seu envolvimento, e descontração durante a atividade, podemos notar a participação de Lucas quando ele se refere a uma imagem, "um balãozinho”, que ilustrava a página do texto e acabou por desencadear a observação para a sala toda, com relação às demais ilustrações que aparecem no livro. Houve muito alvoroço, mas não foi necessária uma cobrança severa de disciplina. As crianças participavam da atividade e elas também cobravam a leitura dos "balõezinhos" que ilustram o texto, algo que sem as suas interferências não teria ocorrido, pois não estava previsto na organização inicial da atividade. E esses "balõezinhos", certamente, nesse texto constituem um mediador importante de

\footnotetext{
${ }^{5}$ Os nomes mencionados são fictícios, por questões éticas em relação à identidade das crianças envolvidas.
} 


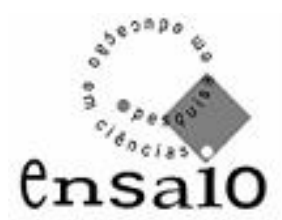

Vol. 10 no 1 jun. 2008

informações ao leitor. Essa foi uma das evidências de que, mesmo a leitura em voz alta tendo sido feita basicamente pela pesquisadora professora, as crianças estavam participando ativamente dessa leitura.

Como considera Silva (2002) as imagens fazem parte das atividades nãoescolares dos estudantes, são fortes componentes do cotidiano deles. Talvez, por isso, elas signifiquem tanto para eles.

Nos destaques a seguir podemos novamente notar a participação de crianças nas manifestações de outras crianças, nessa leitura coletiva:

Gustavo: "- Olha tia! Na camiseta de um esquilo tá escrito: 'comigo é na porrada'."

Camila: "- Quer dizer que esses que estão com a Benedita são bonzinhos?".

Bruno: "- Não! Você não viu que tá escrito no livro que os esquilos vermelhos são bonzinhos e os cinzas, não?"

Camila: "- Alá tia! O vermelho tá dando comida pro cinza. Coitado, tá sendo enganado!"

Camila refaz sua interpretação da imagem a partir da interferência de Bruno. De acordo com Silva, em trabalho no qual também se apóia na mesma vertente da análise do discurso: “(...) O espaço discursivo da sala de aula, mediado por essas questões é, antes de tudo, um espaço constituído também pela voz dos estudantes, seus saberes, memórias, interesses, curiosidades.” (Silva, 2002, p. 136).

Nos trechos seguintes, destacamos como condição de produção das interpretações das crianças falas da pesquisadora que estava atuando como professora na mediação de generalizações:

Gustavo: "- Tia, ele tá falando: 'Pupas... Pupas... Para que pupas?" O que é essa palavra, pupas?"

Pesquisadora: "- Alguém sabe o que é pupa?

Beatriz: "- É o filhotinho da pulga."

Pesquisadora: "- Só da pulga?"

Beatriz: "- Não é?"

Pesquisadora: "- A pupa é uma fase de desenvolvimento dos insetos, um 


\section{, \\ ensa10}

Vol. 10 no 1 jun. 2008

estágio 'dos filhotinhos'. A fêmea põe os ovos, eles se transformam em larva e depois em pupa, que tem uma casca mais dura que o ovo. A pulga é um inseto também."

Nesses destaques, podemos notar que durante a leitura coletiva os gestos de interpretação das crianças não se restringiram à decodificação do texto. Com sua pergunta, Gustavo imprime novo rumo ao funcionamento do discurso em classe, e Beatriz mostra em sua fala a relação com a memória constitutiva, com outros momentos em que a pupa foi associada à pulga. E nesse movimento discursivo, notamos as mediações da professora pesquisadora. Com um interdiscurso mais abrangente no que tange ao discurso científico, ela procura ampliar as interpretações das crianças para além dos sentidos que a leitura do texto e suas memórias constitutivas lhes permitiam até então.

Uma nova pergunta sobre o texto.

$$
\begin{aligned}
& \text { Coro: "- Animais que têm ossos." } \\
& \text { Pesquisadora: "- E bípede?" } \\
& \text { Gustavo: "- Não sei." }
\end{aligned}
$$

Com um incentivo da professora da sala,

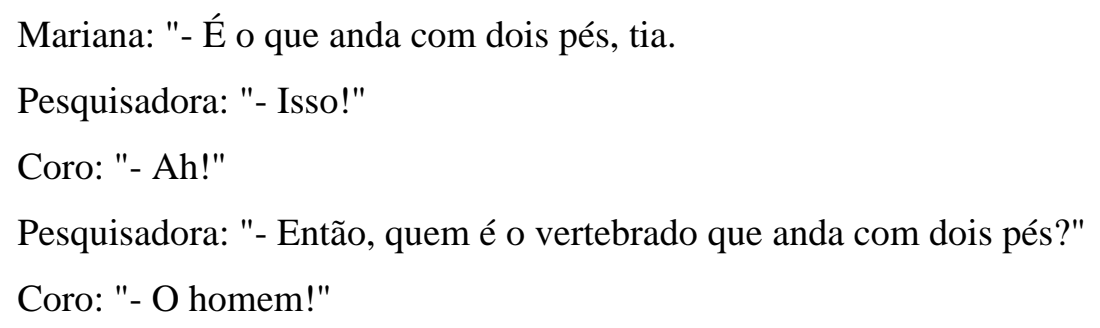

Com as relações estabelecidas: criança-criança, a mediação da professora da sala e a da pesquisadora, à semelhança do que diz Vygotsky (1988), eles estavam construindo formas culturais internamente. Re-elaboravam seus conhecimentos, mediante o estabelecimento de uma nova relação cognitiva com o mundo e seu próprio pensamento.

Pesquisadora: "- O que vocês acham que vai acontecer?" 
Alguns alunos: "- Não sei!"

Outros alunos: "- A Benedita vai ver uma cobra."

Outros ainda: "- Ela vai morrer!"

Pesquisadora: "- Ah! Assim não vale! Vocês foram olhar no final?"

Coro: "- Riram."

Até os que não tinham olhado foram verificar o final do livro, não resistiram.

Pesquisadora: "- Agora vocês já sabem o que vai acontecer, mas vamos continuar?"

Coro: "- Vamos, tia!"

É interessante notar o interesse dos estudantes em cada trecho do texto e não apenas na trama que leva a um final, feliz ou não. A partir da leitura do texto e das imagens, as crianças foram elaborando suas interpretações.

Alguns estudantes: "- Tá legal, tia!"

Imitaram, em coro o barulho que fez quando Benedita matou a cobra: "'Bonc! Bonc!' e riram.

(...)

Natália: "- Tia, as formiguinhas já tão indo lá na cobra morta!"

Pesquisadora: "- É mesmo!"

Todos em coro: "Fim!"

Houve um alvoroço.

Pesquisadora: "-Esperem, ainda não acabou a história! Vocês esqueceram do 'minhoquinho'?"

Lucas: "- Tia, olha o que ela falou: '- Quem pôs o bumbum na mesa?"'

Todos riram. E foi a partir da leitura de uma imagem que os estudantes voltaram a participar da leitura do texto.

Rodrigo: "- O pai falou: '- Esse garoto só dá prá isca!"

Mais um alvoroço na sala.

Natália: "- Tia! Uma vez eu fui pescar com o meu pai."

Pesquisadora: "- Pessoal, a Natália tem uma história sobre pescaria para 
Nesse momento a pesquisadora acreditou que Natália quisesse contar sua experiência para a classe, talvez fosse falar mais sobre as minhocas, mas ela ficou envergonhada e não continuou. De acordo com Silva (2002) não é suficiente "dar" voz aos estudantes no espaço escolar, mas compreender que esta voz é constituída histórica e ideologicamente, numa instituição que, ao regular a produção de sentidos, regula simultaneamente a produção dos sujeitos. A voz das crianças é constituída da memória relacionada com a imagem que têm de si e do outro no espaço institucional.

No final da história todos riram e começaram a folhear o livro novamente, verificando os detalhes das imagens. Alguns alunos demonstraram interesse em expor comentários após a leitura.

A aluna Mariana mostrou que o cadáver da Benedita aparece logo no início do livro, e não havíamos reparado, demonstrando o quanto as imagens no texto lhe chamaram a atenção. Para Chartier (2001), a leitura de uma imagem "pode ser entendida como metáfora” (Chartier, 2001: 142), pois a leitura de um texto pertence ao mundo das práticas discursivas. Ela não pode ser pensada conforme os mesmos procedimentos e as mesmas técnicas da leitura de um texto, pois possuem um objeto distinto. A leitura de um texto não é igual à "leitura” de uma imagem, pois as técnicas e os procedimentos são de outra natureza, determinadas por esforços cognitivos distintos, por lógicas que não são idênticas.

Pedro comentou que já sabia que as formigas-amazonas são escravizadoras de outras espécies de formigas, pois já havia lido em uma revista, "fora da escola". Dessa maneira, ele historicizou seu dizer, ou seja, retomou algo que já sabia, sua memória discursiva para relacionar com a informação trazida pelo autor.

Como afirma Orlandi (apud Almeida, 1998), o texto em si é incompleto, pois tem a ver com a exterioridade, ou seja, o contexto em que se dá a leitura e com outros textos - a intertextualidade. A leitura, como interação social, mediada pelo texto, nunca é unívoca e estática. Um mesmo texto pode ser lido de forma diferente por uma pessoa em diferentes momentos de sua vida. O leitor pode também procurar saber o que o autor quis dizer, de acordo com a época em que viveu e qual a relação de um texto com outro. 


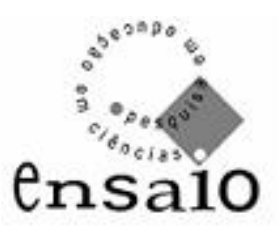

Vol. 10 no 1 jun. 2008

\section{UMA Última CONSIDERAÇão}

Colocado em funcionamento na escola o texto de literatura infantil, trouxe uma construção de conceitos para as crianças, sem priorizar conteúdos específicos, mas considerando as relações ambientais como um todo. Possibilitou reflexões de natureza ecológica no sentido de conhecer e julgar a própria realidade.

Retomando Orlandi (1996), buscamos compreender os sentidos dados pelas crianças a partir do objeto simbólico livro, considerando que

(...) a interpretação é uma injunção. Face a qualquer objeto simbólico, o sujeito se encontra na necessidade de "dar" sentido. O que é dar sentido? Para o sujeito que fala, é construir sítios de significância (delimitar domínios), é tornar possíveis gestos de interpretação (Orlandi, 1996: 64)

A leitura coletiva, com as mediações da pesquisadora e das próprias crianças, possibilitou a apreensão de conhecimentos referentes ao ensino de ciências e do meio ambiente. Ao retomarmos o funcionamento do texto na atividade proposta notamos que algumas crianças re-elaboraram seus conhecimentos, relacionando a leitura do texto e de suas imagens com sua memória.

O referencial teórico da Análise de Discurso de linha francesa, possibilitou-nos compreender que os sentidos não emanam das coisas ou dos sujeitos, mas são produzidos pela história, pela ideologia, enfim, por suas condições de produção. Ou seja, como nos orienta Orlandi (2005), podemos compreender o que o sujeito diz, considerando que esse dizer é determinado pela exterioridade na sua relação com os sentidos.

\section{REFERÊNCIAS}

ALMEIDA, Maria José P. M. O texto escrito na educação em física: enfoque na divulgação científica. In: ALMEIDA, Maria José P. M e SILVA, Henrique César da (orgs.). Linguagens, leituras e ensino da ciência. Campinas, SP: Mercado de Letras: Associação de Leitura do Brasil - ALB, 1998. p.53-68. 


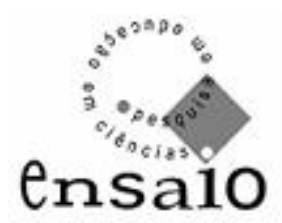

Vol. 10 no 1 jun. 2008

ARROYO, M. G. A função social do ensino de ciências In: Em Aberto, ano 7, n. 40, out/dez., 1988.

BACHELARD, Gaston. A formação do espírito científico: contribuição para uma psicanálise do conhecimento. Rio de Janeiro: Contraponto, 1996.

CHARTIER, Roger. Cultura escrita, literatura e história: Conversas de Roger Chartier com Carlos Aguirre Anaya, Jesús Anaya Rosique, Daniel Goldin e Antonio Saborit. Porto Alegre: ARTMED, 2001.

COELHO, Betty. Contar histórias: uma arte sem idade. São Paulo: Ática, 1997.

KAUFMAN, Ana Maria e RODRİGUEZ, Maria Elena. Escola, leitura e produção de textos. Trad. Inajara Rodrigues. Porto Alegre: Artes Médicas, 1995.

LARSON, Gary. Tem um cabelo na minha terra!: uma história de minhoca. Ilustrações do autor; tradução de Heloísa Jahn; prefácio de Edward O. Wilson. São Paulo: Companhia das Letrinhas, 2002.

LOPES, Alice R. C. Contribuições de Gaston Bachelard ao ensino de ciências In:

Enseñanza de Las Ciências, 1993, 11 (3), p. 324 - 330.

OLIVEIRA, Odisséa B. de. Possibilidades da escrita no avanço do senso comum para o saber científico na $8^{a}$ série do ensino fundamental. 2001. 157f. Dissertação (Mestrado) - Faculdade de Educação, Universidade Estadual de Campinas.

ORLANDI, Eni P. Análise do discurso: princípios e procedimentos. Campinas, SP: Pontes, 6a . ed., 2005.

RJ: Vozes, 1996.

Interpretação; autoria, leitura e efeitos do trabalho simbólico. Petrópolis, Discurso \& Leitura. Campinas: Cortez Editora/Editora da Unicamp, 1988.

RICON, Alan, ALMEIDA, Maria José P. M. de. Ensino de Física e Leitura In: Leitura Teoria e Prática, Ano 10 n¹8, 7-16, Dez/1991.

SILVA, Henrique César da. Discursos escolares sobre gravitação newtoniana: textos e imagens na física do ensino médio. 2002. Tese (Doutorado) - Faculdade de Educação, Universidade Estadual de Campinas.

SNYDERS, Georges. Para onde vão as pedagogias não-directivas? Lisboa, Portugal: Moraes Editores, 2 ed., 1978.

VYGOTSKY, L. S. A formação social da mente. São Paulo: Martins Fontes, 1988. Pensamento e Linguagem. Tradução de Jeferson Luiz Camargo. São Paulo:

Martins Fontes, 1993. 